\section{Human reliability analysis: a new method to quantify errors in cataract surgery}

Department of

Ophthalmology, Ninewells University Teaching Hospital, Dundee, UK

Correspondence: A Cox Department of Ophthalmology, Ninewells University Teaching Hospital, Ninewells Ave, Dundee, Tayside DD1 9SY, UK

Tel: + 441382 632713;

Fax: + 441382632893

E-mail: alan.cox@

tuht.scot.nhs.uk

Received: 4 January 2006 Accepted in revised form: 28 July 2006

Published online:

23 February 2007

\begin{abstract}
Purpose To describe the application of human reliability analysis (HRA) as a tool to quantify errors that occur during small incision cataract surgery.

Methods Sixteen consecutive phacoemulsifications performed by one surgeon were assessed using HRA.

Results Although there were no complications or adverse outcomes associated with any of the operations, 84 errors, which could potentially have caused a complication were noted. The commonest single error was difficulty in 'cracking' the nucleus.

Conclusions HRA attempts to recognise all errors that occur during a procedure rather than just the ones that result in a complication. As such it is a sensitive and prospective method of assessment of surgical performance. It would appear to be of value in the training and assessment of cataract surgery.

Eye (2008) 22, 394-397; doi:10.1038/sj.eye.6702648; published online 23 February 2007

Keywords: human; reliability; analysis; cataract; audit; training

\section{Introduction}

Traditionally assessment of surgical competence and surgical teaching has revolved around audit of surgical complications or adverse outcomes. This has several problems. It is by its nature retrospective in that the adverse outcome has already occurred. In addition, surgeons may be tempted to alter their case mix to avoid more difficult cases. In many industries such as the nuclear power or aerospace industry, the consequences of errors are catastrophic and so such a retrospective approach is considered unacceptable. The methodology of human reliability assessment (HRA) has been
\end{abstract}

A Cox, L Dolan and CJ MacEwen

developed within these areas as an alternative strategy. ${ }^{1}$ This methodology determines what may go wrong, the probability and consequences of errors, and the steps necessary to reduce the incidence of such errors to as low as reasonably possible. The prospective and prescriptive nature of this methodology makes it attractive as a measure of surgical performance ${ }^{2}$ and it has been successfully adapted for use with other surgical specialities. ${ }^{3,4}$

The purpose of our study is to describe the use of this approach in the assessment and teaching of small incision cataract surgery.

\section{Methods}

Task analysis was performed to determine the chronological steps involved in cataract extraction by phacoemulsification (Table 1). Sixteen consecutive cases performed by one surgeon (LD) were recorded on S-VHS tape. A conventional divide and conquer technique was employed in all cases. The recordings were then analysed by a more experienced surgeon (AC) and any errors noted. The errors were categorised using external error modes piloted for physical procedural tasks $\mathrm{s}^{3,5}$ and the step at which they occurred was noted (Table 2).

Additionally, the potential severity of the error was also recorded (Table 3 ).

\section{Results}

In total, 84 errors were noted. None were associated with a complication or adverse outcome, 28 (33\%) of the errors were categorised as minor, $49(58 \%)$ as rarely associated with an adverse outcome, and seven $(8.3 \%)$ as often associated with an adverse outcome. These seven more severe errors are described in more detail in Table 4. 
Table 1 Task analysis

\begin{tabular}{|c|c|c|c|c|}
\hline No & Task & Plan & Subtask & Description \\
\hline 1 & Anaesthesia & & & \\
\hline 2 & Draping & & & \\
\hline \multirow[t]{3}{*}{3} & $\begin{array}{l}\text { Create access and } \\
\text { maintain AC }\end{array}$ & $\begin{array}{l}\text { Do subtasks } 3.1 \text { and } 3.2 \text { in any order. } \\
\text { Do subtask } 3.3 \text { between } 3.1 \\
\text { and } 3.2 \text { if necessary }\end{array}$ & 3.1 & Create paracentesis \\
\hline & & & 3.2 & Create tunnel \\
\hline & & & 3.3 & Inflate AC with viscoelastic \\
\hline \multirow[t]{3}{*}{4} & Create capsularhexis & Do subtasks $4.1-4.3$ in consecutive order & 4.1 & Linear incision in anterior capsule \\
\hline & & & 4.2 & Elevate flap of anterior capsule \\
\hline & & & 4.3 & Create continous circular capsularhexis \\
\hline 5 & Hydrodisection & & 5.1 & Hydrodisect lens \\
\hline \multirow[t]{3}{*}{6} & $\begin{array}{l}\text { Divide lens into } \\
\text { fragments }\end{array}$ & $\begin{array}{l}\text { Iterate through subtasks } 6.1,6.2 \text {, and } \\
6.3 \text { till objective compleated }\end{array}$ & 6.1 & Grove lens with primary phaco \\
\hline & & & 6.2 & Rotate nucleus \\
\hline & & & 6.3 & Crack nucleus \\
\hline \multirow[t]{4}{*}{7} & Secondary phaco & Iterate through steps 7.1-7.4 & 7.1 & Engage lens fragment with phaco probe \\
\hline & & & 7.2 & Withdraw lens fragment to within the pupil plane \\
\hline & & & 7.3 & Aspirate lens fragment \\
\hline & & & 7.4 & Rotate lens nucleus \\
\hline \multirow[t]{3}{*}{8} & I/A of cortex & Iterate through steps $8.1-8.3$ & 8.1 & Engage cortex \\
\hline & & & 8.2 & Withdraw centrally \\
\hline & & & 8.3 & Aspirate cortex \\
\hline \multirow[t]{4}{*}{9} & Insert IOL & $\begin{array}{l}\text { Perform steps } 9.1,9.2 \text {, and } 9.3 \\
\text { sequentially }\end{array}$ & 9.1 & Inflate capsular bag with viscoelastic \\
\hline & & & 9.2 & Enlarge wound \\
\hline & & & 9.3 & Fold IOL \\
\hline & & & 9.4 & Insert IOL \\
\hline \multirow[t]{2}{*}{10} & Final checks & Perform steps 10.1 and 10.2 & 10.1 & Remove viscoelastic \\
\hline & & Perform 10.3 or 10.4 if necessary & 10.2 & Check wound integrity \\
\hline
\end{tabular}

Table 2 External error modes

1. Step is not performed

2. Step is partially completed

3. Step is repeated

4. Second step is performed in addition

5. Second step is performed instead of first step

6. Step is performed out of sequence

7. Step is performed with too much (speed, force, distance, time, rotation, depth)

8. Step is performed with too little (speed, force, distance, time, rotation, depth)

9. Step is performed in wrong (orientation, direction, point in space)

10. Step is performed on/with wrong object

Table 3 Grading of potential severity of error

1. Minor error that almost never causes an adverse outcome

2. Error that can potentially cause an adverse outcome but does so rarely

3. Error that often causes an adverse outcome

4. Recognised complication causing an adverse outcome

Twenty-one (25\%) of the errors occurred during cracking of the nucleus, 10 (12\%) occurred during primary phaco, and the rest occurred at various other
Table 4 Description of errors that often cause an adverse outcome

\begin{tabular}{lc}
\hline Description & Number of occurrances \\
\hline Poor control of capsularhexis & 2 \\
Small capsularhexis & 1 \\
Incomplete cracking of nucleus & 2 \\
Excessive posterior force on nucleus & 2 \\
\hline
\end{tabular}

stages of the procedure (Figure 1). The error mode was 'step done in wrong orientation, direction, or point in space' in $36(43 \%)$ of errors and 'step partially completed' in $26(31 \%)$ of errors.

The commonest single errors were difficulty in 'cracking' the nucleus owing to poor instrument placement $(13 \%)$ and unrecognised failure to completely crack the nucleus (12\%). Errors occurred less frequently as the surgeon gained in experience (Figure 2).

\section{Discussion}

The number of errors recorded is comparable with studies from other surgical fields. In other studies, 


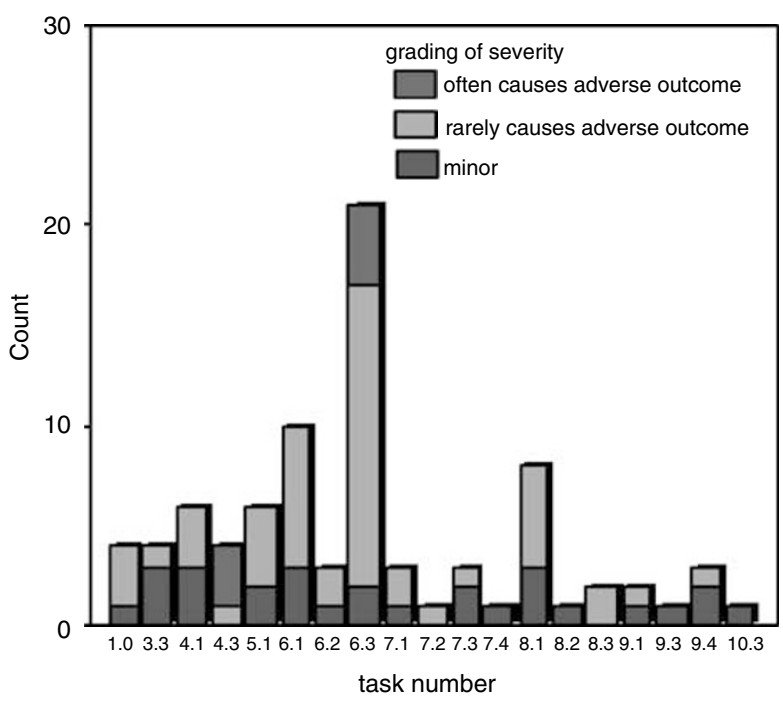

Figure 1 Tasks associated with errors.

189 errors were recorded in 20 laproscopic cholecystectomies $^{3}$ and 100 errors were recorded in 12 endoscopic DCRs. ${ }^{4}$ It is important to stress that even experienced surgeons seldom perform a perfect error-free cataract extraction (even if they think they do). An error is not the same as a complication.

Traditional audit only records those errors that result in a complication or adverse outcome. The methodology outlined above is more sensitive in that lessons are drawn from all potential errors. An analogy can be drawn with a driver who loses control of a car on black ice. He may regain control without incident or the incident may occur next to a crowded bus stop and result in fatalities. The result of the error depends on luck and external factors and it would be foolish to ignore errors that we 'get away with'. Similarly, the Clapham rail disaster was at source owing to wiring errors; however, the same errors were subsequently found in many other signal relays. It was not the first time that the error had occurred; it was merely the first time that a 'complication' arose from the error. Analysing errors rather than complications allows us to anticipate and hopefully prevent the adverse outcome.

In this study, the trainee had performed very few cataract extractions at the start of the assessment process, whereas the assessor had performed close to 1000 phacoemulsification procedures. This experience gap ensured that there was little controversy about what constituted an error, and so only one assessor was necessary. If this technique was extended to the assessment of more experienced surgeons, it may be necessary to utilise more than one assessor.

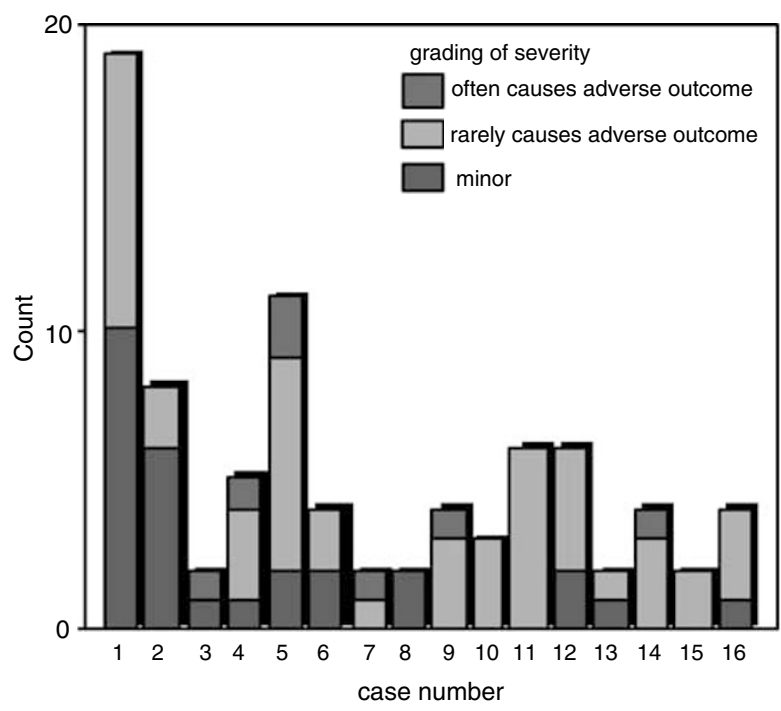

Figure 2 Errors per case.

HRA is a powerful methodology for modelling and preventing accidents and its use in medicine remains in its infancy. Most catastrophic accidents occur owing to a combination of active and latent errors. Active errors can be thought of as 'someone doing something wrong'. They are errors of execution where the correct procedure is known but not followed. Deliberately, we have only described such active errors that are the responsibility of the surgeon as we are attempting to describe surgeon competence. Latent errors are classically 'errors in the system' that are not immediately apparent but in combination with other circumstances cascade into an adverse event. One such latent error was noted in that the $90^{\circ}$ tip for the I/A cannula was not present on the tray, which made the operation more difficult. Although beyond the scope of this study, the impact of such errors should always be considered in investigating an adverse event.

It may be that other forms of surgery, which are less predictable, are less immediately amenable to assessment using this methodology; however, small incision cataract surgery involves predetermined, sequential steps and as such is well suited to assessment by HRA. In summary, HRA as applied above provides an objective framework to analyse cataract surgery and assist in the teaching of such surgery.

\section{References}

1 Embrey DE, Humphreys P, Rosa EA, Kirwan B, Rea K. SLIM-MAUD: an approach to assessing human error probabilities using structured expert judgement, USNRC Report Nureg/CR-3518. United States Nuclear Regulatory Committee: Washington, DC, 1984. 
2 Cuschieri A. Human reliability assessment in surgery - a new approach for improving surgical performance and clinical outcome. Ann R Coll Surg Engl 2000; 82: 83-87.

3 Joice P, Hanna GB, Cuschieri A. Errors enacted during endoscopic surgery - a human reliability analysis. Appl Ergon 1998; 29: 409-414.
4 Malik R, White PS, MacEwen CJ. Using human reliability analysis to detect surgical error in endoscopic DCR surgery. Clin Otolaryngol 2003; 28: 456-460.

5 Embry DE. SHERPA: a systematic human error reduction and prediction approach. Presented at the International Topical Meeting on Advances in Human Factors in Nuclear Power Systems, Knoxville: TN 1986. 